\title{
Adult pancreatic hemangioma in pregnancy - concerns and considerations of a rare case
}

\author{
Jon Arne Søreide ${ }^{1,4^{*}}$, Ole Jakob Greve ${ }^{2}$ and Einar Gudlaugsson ${ }^{3}$
}

\begin{abstract}
Background: Pancreatic tumors in pregnancy are rare but clinically challenging. Careful diagnostic workup, including appropriate imaging examinations, should be performed to evaluate surgery indications and timing. In the present case a diagnosis of an adult pancreatic hemangioma was made. We were not able to identify a similar case in the very sparse literature on this rare disease.

Case presentation: A 30-year-old woman at 12 weeks of gestation was diagnosed with a large pancreatic tumor having a cystic pattern based on imaging. Although the preoperative diagnosis was uncertain, patient preference and clinical symptoms and signs suggested surgery. Open distal pancreatic resection including splenectomy was performed, and complete resection of the large cystic tumor was successfully achieved, with no postoperative complications. Although a solid pseudopapillary epithelial neoplasm (SPEN) was suspected, specimen morphology, including immunohistochemistry, supported the diagnosis of an adult benign pancreatic hemangioma.

Conclusion: Although mucinous cystic neoplasm (MCN) and adenocarcinoma are the most common pancreatic tumors during pregnancy, various other malignant and benign lesions can be encountered. This report adds to the very small number of pancreatic hemangiomas reported in the literature and involves the first patient diagnosed with this rare condition during pregnancy. Careful clinical considerations regarding diagnostic workup and treatments are required to ensure that mother and child receive the best possible care.
\end{abstract}

Keywords: Cystic lesion, Hemangioma, Pancreas, Pregnancy

\section{Background}

In pregnant women, the acute abdomen is often a challenge. Careful clinical evaluation, close cooperation between the surgeon and the gynecologist as needed, and the application of appropriate diagnostic tools and educated judgment remain the cornerstones of standard care [1-6]. Although the diagnostic workup can be demanding in these cases, a responsible surgeon might regard appropriate surgical treatment as stressful for the relatively common diseases encountered during pregnancy such as appendicitis $[7,8]$ and acute cholecystitis $[9,10]$. A surgeon is confronted by even greater responsibility for a mother and her child in clinical settings involving rare acute abdominal conditions of pregnancy, which include acute severe pancreatitis [11], gastrointestinal

\footnotetext{
*Correspondence: jonarne.soreide@uib.no

'Department of Gastrointestinal Surgery, Stavanger University Hospital, N-4068 Stavanger, Norway

${ }^{4}$ Department of Clinical Medicine, University of Bergen, Bergen, Norway

Full list of author information is available at the end of the article
}

bleeding [12, 13], and suspected tumors in various locations [14-19]. In cases involving a cystic lesion, the nature of the lesion, including its malignant potential and the risk of a spontaneous rupture, must be considered when discussing indications for and the timing of surgery $[15,20]$. In this situation, the surgical approach, which varies depending on the pregnancy trimester is a particularly concerning issue.

In this report, we discuss clinical considerations related to the unexpected finding of a large cystic lesion that appears to be related to the pancreas in a pregnant woman with acute abdomen.

\section{Ethics}

Written informed consent was obtained from the patient for publication of this Case report and any accompanying images. A copy of the written consent is available for review by the Editor of this journal.

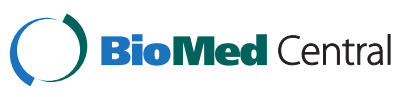




\section{Case presentation}

An otherwise healthy, non-obese 30-year-old woman, para 0 , at 12 weeks gestation was admitted to our hospital's Department of Gastrointestinal Surgery with a history of 3 weeks of varying but increasing pain in the left upper quadrant of her abdomen and nausea without vomiting. A palpable left subcostal mass was detected by clinical examination, which revealed no other notable findings except for her pregnant status. Ultrasound (US) examination (Fig. 1) revealed a large cystic lesion (size, $17 \times 10 \mathrm{~cm}$ ) with septa related to the tail of the pancreas and spleen. Magnetic resonance imaging (MRI) depicted a multicystic lesion related to the pancreatic tail, between the spleen and left kidney, with moderate dislocation of both the kidney and spleen (Fig. 2). Routine biochemistry was normal, and tumor markers carcinoembryomic antigen $(\mathrm{CEA}=4 \mu \mathrm{g} / \mathrm{l})$, cancer antigen $125(\mathrm{CA} 125=42 \mathrm{kU} / \mathrm{l})$, carbohydrate antigen 19-9 (CA19-9 < $5 \mathrm{kU} / \mathrm{l})$, and chromogranin $\mathrm{A}(\mathrm{CgA}=2.8 \mathrm{nmol} / \mathrm{l})$ were all within normal ranges. The preoperative diagnosis was uncertain; however, based on imaging findings and the patient's young age, a solid pseudopapillary epithelial neoplasm (SPEN) was considered. A gynecologist evaluated the patient's pregnancy as normal. Relevant factors when considering indications for surgery included the presence of increasing clinical symptoms in a pregnant woman, the uncertain nature of the rather large cystic pancreatic tumor, and the possible risk and undesirable consequences of a rupture of this tumor during the second or third trimester. In accordance with the patient's preferences, surgical treatment was recommended. Open resection of the most distal portion of the pancreas, including the large cystic tumor and spleen, was performed. Frozen sections of the pancreas resection border confirmed that the resected tissue was benign. The patient's postoperative course was uneventful, and she was able to leave the hospital on the $6^{\text {th }}$ postoperative day without complications.

The multicystic tumor (Fig. 3) measured $19.5 \times 10 \times 7 \mathrm{~cm}$ and exhibited close adherence to the distal pancreas but without infiltration in the pancreas parenchyma or any communication with the pancreatic ducts. Microscopically, benign pancreatic tissue was confirmed, and the tumor was multicystic with extremely thin septa, fibrosis and a pattern of chronic inflammation, but no epithelial tissue indicating that SPEN was unlikely. Additional immunohistochemistry (IHC) with CD34 and CD 31 (Fig. 4) provided information to support a large-vessel hemangioma lined with single endothelial layer without cytologic atypia, and with focal degenerative changes in septa and the cystic wall. This endothelial lining was negative for cytokeratins and calretinin, excluding epitehelial and mestothelial nature of the lesion Taken together, the tumor morphological findings were characteristic of a truly benign lesion most consistent with adult pancreatic hemangioma, which was resected completely without any ruptures.

After surgery, the patient's pregnancy proceeded uneventfully, and she spontaneously delivered a healthy child

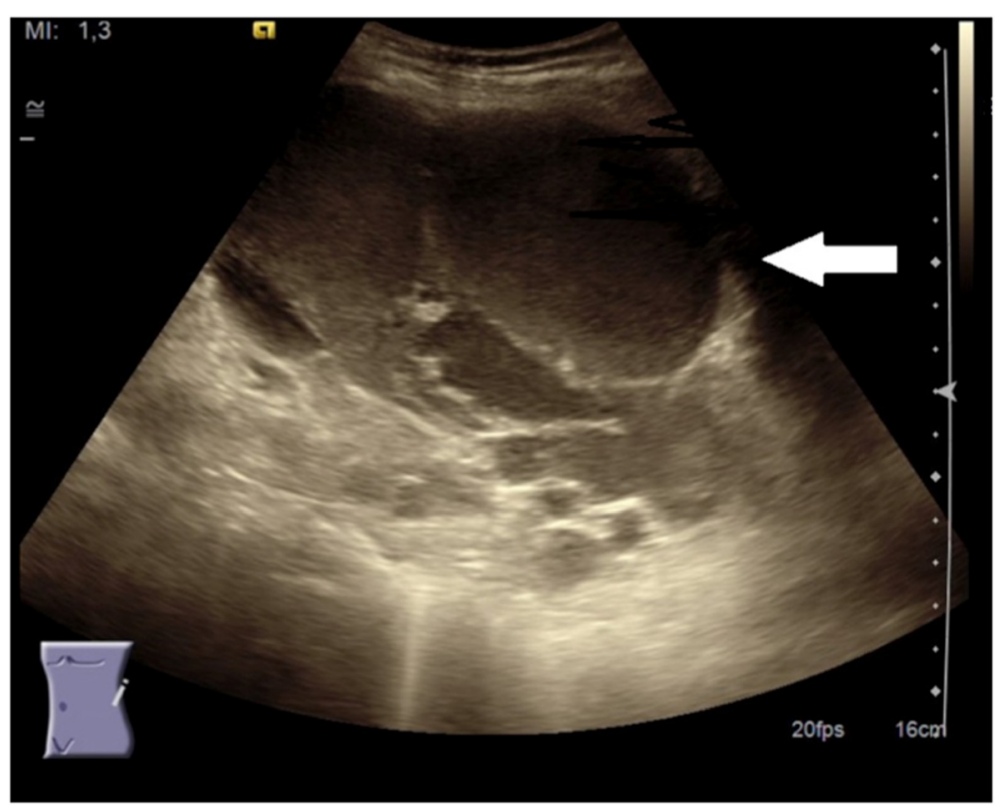

Fig. 1 Ultrasound showed a large cystic lesion with septa and some sedimentation. Minimal Doppler signal of the large tumor (18 $\times 10 \mathrm{~cm}$ ). Spleen, pancreas and left kidney without focal lesions 


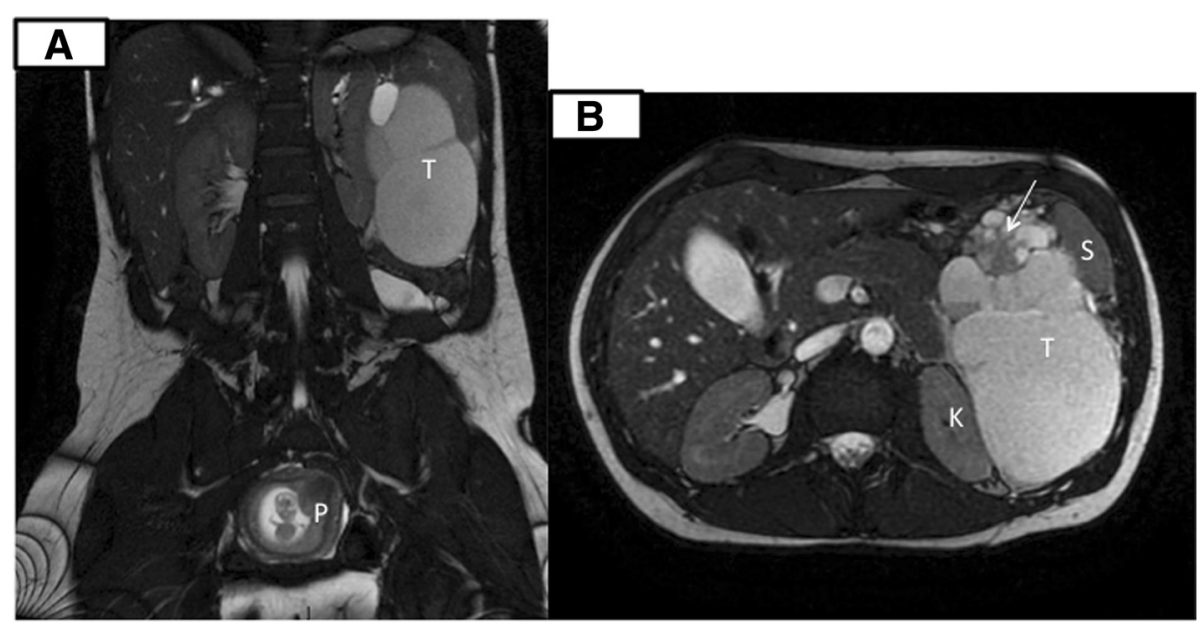

Fig. 2 Coronal (a) and transversal (b) MRI T2 (FIESTA) view. Large tumor (T) medial to the spleen (S) and adjacent to the pancreatic tail dislocating the left kidney $(\mathrm{K})$ medial and cranial. Mostly high signal intensity at T2 and intermediate to high at T1, indicating cystic components with protein or blood. A smaller part of the lesion had lower signal and diffusion restriction indicating more solid parts. $(P)$ is the pregnant uterus. A solid pseudopapillary epithel neoplasia (SPEN) of the pancreas was suspected in this young woman with an encapsulated lesion with cystic, solid and hemorrhagic components

at the calculated gestational time. During follow-up of at least 12 postoperative months, the patient has expressed no complaints or concerns related to her treatment.

\section{Discussion}

While hemangiomas are rarely found in the pancreas, they are very common in the liver. Mundinger et al. reviewed the literature and found only 9 cases with confirmed adult pancreatic hemangiomas reported between 1939 and 2009 [21]. The lesions were most commonly located in the head, or head/body of the gland, with a size varying from $3 \mathrm{~cm}$ to $20 \mathrm{~cm}$ in diameter. Recently, Bursics and coworkers [22] reported on another patient (a 72-year-old man) surgically treated for a confirmed adult hemangioma of the pancreas, and presented relevant data on the 12 reported cases, including their own, published until 2013. Male:female ratio was found to be $2: 1$, and the median age was 61 (range, 30-79) years. As demonstrated by these 12 reported cases in the world literature $[21,22]$, pain was the most common clinical symptom which was also the case in our patient. The pattern of a suggested cystic lesion by imaging was

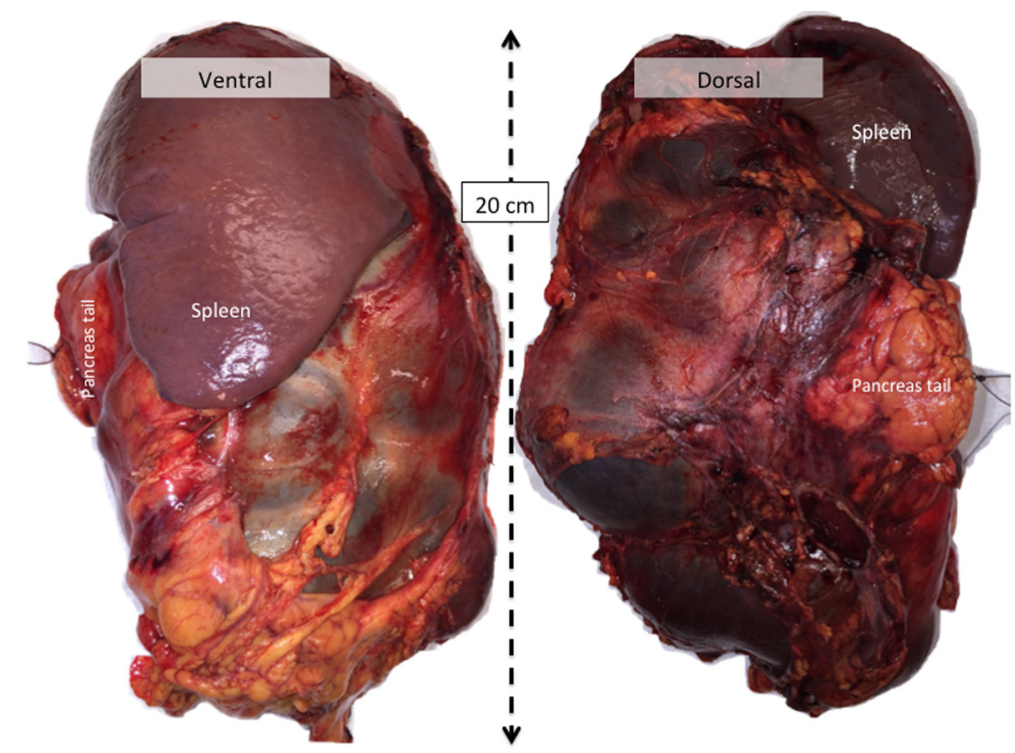

Fig. 3 Operative specimen with the cystic tumor and the spleen seen from the ventral (left) and the dorsal (right) side. The cystic tumor measured $19.5 \times 10 \times 7 \mathrm{~cm}$ 


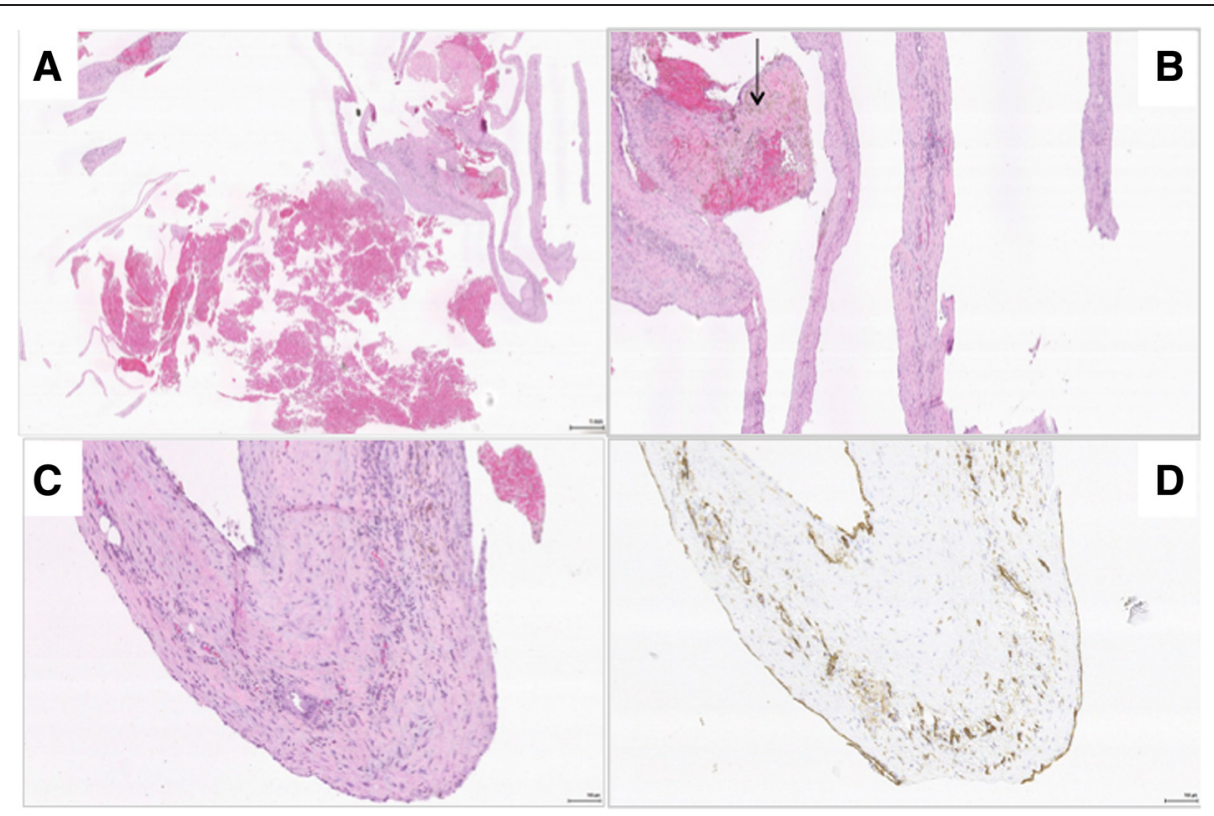

Fig. 4 a Large dilated vascular structures lined by endothelial cells filled with red blood cells. The thickened vessel walls are composed of fibrous or spindle cell stroma with mild chronic inflammation. ( $\mathrm{H}$ and $\mathrm{E}$; original magnification: $\times 10)$. $\mathbf{b}$ Large dilated vascular structures lined by endothelial cells filled with red blood cells. The thickened vessel walls are composed of fibrous or spindle cell stroma with mild chronic inflammation and hemosiderin loaded macrophages (arrow) ( $H$ and E; original magnification: $\times 20)$. c Microscopy showing large dilated vascular structure lined by endothelial cells. The wall is infiltrated with mild chronic inflammation. ( $\mathrm{H}$ and E; original magnification: $\times 100$ ). d. Immunohistochemical expression of CD31 (brown) depicting the endothelial lining of larger vascular spaces and small vessels in the stroma (original magnification, $\times 20$ )

found in most patients with available information in this regard. Notably, the CT patterns of a pancreatic hemangioma are different from the CT signs of a liver hemangioma, as a typical early peripheral contrastenhancement during the arterial phase is missing in the former [23]. Therefore, this imaging modality is ineffective for ruling out pancreatic hemangioma.

Our patient was definitely in the younger range of age, and importantly, we report on the first pregnant patient diagnosed with an adult pancreas hemangioma. Although the final morphologic diagnosis of this rare condition can be challenging, CD 31 and CD 34 immunohistochemical labeling adds valuable support to the diagnosis of a neoplasm of vascular origin [21].

Both benign and malignant pancreatic neoplasms are rarely diagnosed during pregnancy; in particular, pancreatic cancer during pregnancy is extremely rare, with fewer than 10 described cases to date $[15,16]$. However, a number of dilemmas can be encountered when attempting to determine an accurate diagnosis to enable appropriate treatment. Within this context, both US and MRI are reliable and useful imaging modalities $[5,20]$ without known health risks for the fetus [24]. When indicated, CT can also contribute to imaging findings. Of note, the risk that the fetus will develop congenital abnormalities due to the side effects of radiation exposure (via repeat and/or multiphase CT scans) is considered to be extremely low [25], nonetheless, due to concerns regarding the potential for deleterious side effects, radiation and various contrast agents should be limited and used with care [24, 25].

Del Chiaro et al. [26] recently demonstrated that the overall accuracy of preoperative diagnoses of cystic pancreatic lesions is only approximately $60 \%$, with similar accuracies for asymptomatic and symptomatic lesions. Thus, inaccurate preoperative assessments of pancreatic cystic lesions are common; however, diagnostic errors are clinically relevant in less than $10 \%$ of these cases. Data regarding lesion size, patient gender, and the patient's prior history (with respect to pancreatitis or other relevant diseases) could be valuable information for reaching appropriate decisions and thereby preventing the overutilization of operative resection in patients with these lesions [27]. For non-pregnant patients, additional imaging (e.g., contrast CT scans) and endoscopic ultrasound (EUS)-guided aspiration of the cystic lesion for analyses of DNA mutations and proteins within pancreatic cyst fluid can contribute to the diagnostic workup [20, 28]. However, due to potential risks for a biopsy related bleeding, rupture of the lesion or peritoneal seeding of biopsy material, we did not regard our symptomatic pregnant patient with a large pancreatic lesion as a candidate for this 
diagnostic approach. Her subjective and increasing complaints, the uncertain nature of the lesion, and the risk of tumor rupture with undesired side effects or complications later during her pregnancy, were all important considerations for the timing of treatment. The preoperative diagnosis of a possible SPEN was not definitively determined. As recently suggested [29] SPENs are rare cystic lesions that frequently occur in young women and patients with these lesions exhibit good prognoses if radical surgical resection can be achieved. Despite the challenging nature of a definite diagnosis, the only feature of the described case that could be associated with malignancy was a large tumor size at diagnosis [20,29]. Thus fare, malignancy has not been reported for pancreatic hemangiomas. Based on the rarity of this condition, the lack of reliable follow-up data, and the sparse literature on this topic, an understanding of the pathophysiology and natural history of these lesions remains at an early stage [21].

\section{Conclusion}

Although reports have described a number of anecdotes involving worrisome histories of pregnant women with malignant tumors, including carcinomas of the pancreas $[16,30,31]$, pancreatic neuroendocrine tumors [14], and bleeding neoplasms [32], or spontaneous SPEN rupture [33], these cases are generally exceptions rather than the rule. Nevertheless, given the objective of providing optimal care to both mother and child, the determination of an appropriate treatment schedule for any young pregnant woman requires the consideration of a wide range of diagnoses and a number of important factors. Although the second trimester is considered to be the most favorable time for surgical intervention for pancreatic tumors [15], multidisciplinary consultation should occur with respect to a pregnant patient's diagnosis, indications and timing to ensure that the best possible outcomes for both the mother and the child are achieved [15, 18, 19, 22, 26].

\section{Abbreviations \\ CT: Computer tomography; EUS: Endoscopic ultrasound; \\ IHC: Immunohistochemistry; MCN: Mucinous cystic neoplasm; MRI: Magnetic resonance imaging; SPEN: Solid pseudopapillary epithelial neoplasm.}

\section{Competing interests}

The authors declare they have no competing interests.

\section{Authors' contributions}

Study conception and design: JAS. Data acquision: JAS, OJG, EG. Data interpretation: JAS, OJG, EG. Drafting of the manuscript: JAS. Manuscript editing and final approval: JAS, OJG, EG.

\section{Acknowledgements}

The authors appreciate the patient's consent to present this case.

\section{Author details}

${ }^{1}$ Department of Gastrointestinal Surgery, Stavanger University Hospital, N-4068 Stavanger, Norway. ${ }^{2}$ Department of Radiology, Stavanger University Hospital, Stavanger, Norway. ${ }^{3}$ Department of Pathology, Stavanger University
Hospital, Stavanger, Norway. ${ }^{4}$ Department of Clinical Medicine, University of Bergen, Bergen, Norway.

Received: 6 July 2015 Accepted: 19 October 2015

Published online: 30 October 2015

\section{References}

1. Ackerman SJ, Irshad A, Anis M. Ultrasound for pelvic pain II: nongynecologic causes. Obstet Gynecol Clin North Am. 2011;38:69-83. viii.

2. Boregowda G, Shehata HA. Gastrointestinal and liver disease in pregnancy. Best Pract Res Clin Obstet Gynaecol. 2013;27:835-53.

3. Dewhurst C, Beddy P, Pedrosa I. MRI evaluation of acute appendicitis in pregnancy. J Magn Reson Imaging. 2013;37:566-75.

4. Katz DS, Khalid M, Coronel EE, Mazzie JP. Computed tomography imaging of the acute pelvis in females. Can Assoc Radiol J. 2013;64:108-18.

5. Khandelwal A, Fasih N, Kielar A. Imaging of acute abdomen in pregnancy. Radiol Clin North Am. 2013:51:1005-22.

6. Kilpatrick CC, Orejuela FJ. Management of the acute abdomen in pregnancy: a review. Curr Opin Obstet Gynecol. 2008;20:534-9.

7. Flexer SM, Tabib N, Peter MB. Suspected appendicitis in pregnancy. Surgeon. 2014;12:82-6.

8. Teixeira PG, Demetriades D. Appendicitis: changing perspectives. Adv Surg. 2013;47:119-40.

9. Knab LM, Boller AM, Mahvi DM. Cholecystitis. Surg Clin North Am. 2014;94:455-70.

10. Sucandy I, Tellagorry J, Kolff JW. Minimally invasive surgical management of acute cholecystitis during pregnancy: what are the recommendations? Am Surg. 2013;79:E251-2.

11. Abdullah B, Kathiresan Pillai T, Cheen LH, Ryan RJ. Severe acute pancreatitis in pregnancy. Case Rep Obstet Gynecol. 2015;2015:239068.

12. Friedel D, Stavropoulos S, lqbal S, Cappell MS. Gastrointestinal endoscopy in the pregnant woman. World J Gastrointest Endosc. 2014;6:156-67.

13. Knez J, Day A, Jurkovic D. Ultrasound imaging in the management of bleeding and pain in early pregnancy. Best Pract Res Clin Obstet Gynaecol. 2014;28:621-36

14. Besemer B, Mussig K. Insulinoma in pregnancy. Exp Clin Endocrinol Diabetes. 2010;118:9-18.

15. Boyd CA, Benarroch-Gampel J, Kilic G, Kruse EJ, Weber SM, Riall TS Pancreatic neoplasms in pregnancy: diagnosis, complications, and management. J Gastrointest Surg. 2012;16:1064-71.

16. Kakoza RM, Vollmer Jr CM, Stuart KE, Takoudes T, Hanto DW. Pancreatic adenocarcinoma in the pregnant patient: a case report and literature review. J Gastrointest Surg. 2009;13:535-41.

17. Onuma T, Yoshida Y, Yamamoto T, Kotsuji F. Diagnosis and management of pancreatic carcinoma during pregnancy. Obstet Gynecol. 2010;116 Suppl 2:518-20.

18. Wiseman JE, Yamamoto M, Nguyen TD, Bonadio J, Imagawa DK. Cystic pancreatic neoplasm in pregnancy: a case report and review of the literature. Arch Surg. 2008;143:84-6.

19. Dunkelberg JC, Barakat J, Deutsch J. Gastrointestinal, pancreatic, and hepatic cancer during pregnancy. Obstet Gynecol Clin North Am. 2005;32:641-60.

20. Choi JY, Kim MJ, Kim JH, Kim SH, Lim JS, Oh YT et al. Solid pseudopapillary tumor of the pancreas: typical and atypical manifestations. AJR Am J Roentgenol. 2006;187:W178-86.

21. Mundinger GS, Gust S, Micchelli ST, Fishman EK, Hruban RH, Wolfgang CL. Adult pancreatic hemangioma: case report and literature review. Gastroenterol Res Pract. 2009;2009:839730.

22. Bursics A, Gyokeres T, Bely M, Porneczi B. Adult hemangioma of the pancreas: difficult diagnosis of a rare disease. Clin J Gastroenterol. 2013;6:338-43.

23. Kobayashi $H$, Itoh T, Murata R, Tanabe M. Pancreatic cavernous hemangioma: CT, MRI, US, and angiography characteristics. Gastrointest Radiol. 1991;16:307-10

24. Baysinger CL. Imaging during pregnancy. Anesth Analg. 2010;110:863-7.

25. Patel SJ, Reede DL, Katz DS, Subramaniam R, Antskatlis A. Imaging the pregnant patient for nonobstetric conditions: algorithms and radiation dose considerations. Radiographics. 2007;27:1705-22.

26. Del Chiaro M, Segersvard R, Pozzi Mucelli R, Rangelova E, Kartalis N, Ansorge C, et al. Comparison of preoperative conference-based diagnosis with histology of cystic tumors of the pancreas. Ann Surg Oncol. 2014;21:1539-44. 
27. Allen PJ. Operative resection is currently overutilized for cystic lesions of the pancreas. J Gastrointest Surg. 2014;18:182-3.

28. Kwon RS. Advances in the diagnosis of cystic neoplasms of the pancreas Curr Opin Gastroenterol. 2012;28:494-500.

29. Butte JM, Brennan MF, Gonen M, et al. Solid pseudopapillary tumors of the pancreas. Clinical features, surgical outcomes, and long-term survival in 45 consecutive patients from a single center. J Gastrointest Surg. 2011;15:350-7.

30. Gundling F, Nerlich A, Heitland W, Schepp W. Neuroendocrine pancreatic carcinoma after initial diagnosis of acute postpartal coeliac disease in a 37-year old woman - fatal coincidence or result of a neglected disease? Anticancer Res. 2014;34:2449-54.

31. Hakamada K, Miura T, Kimura A, Nara M, Toyoki Y, Narumi S, et al. Anaplastic carcinoma associated with a mucinous cystic neoplasm of the pancreas during pregnancy: report of a case and a review of the literature. World J Gastroenterol. 2008;14:132-5.

32. Brown TH, Menon VS, Richards DG, Griffiths AP. Gastrointestinal bleeding in a pregnant woman: mucinous cystic neoplasm of pancreas mimicking gastrointestinal stromal tumor of stomach. J Hepatobiliary Pancreat Surg. 2009;16:681-3.

33. Huang SC, Wu TH, Chen CC, Chen TC. Spontaneous rupture of solid pseudopapillary neoplasm of the pancreas during pregnancy. Obstet Gynecol. 2013;121:486-8.

\section{Submit your next manuscript to BioMed Central and take full advantage of:}

- Convenient online submission

- Thorough peer review

- No space constraints or color figure charges

- Immediate publication on acceptance

- Inclusion in PubMed, CAS, Scopus and Google Scholar

- Research which is freely available for redistribution 